\title{
CIENCIAMATRIA
}

Revista Interdisciplinaria de Humanidades, Educación, Ciencia y Tecnología

Año VII. Vol. VII. N¹2. Enero - Junio. 2021

Hecho el depósito de ley: pp201602FA4721

ISSN-L: 2542-3029; ISSN: 2610-802X

Universidad Nacional Experimental Francisco de Miranda (UNEFM). Santa Ana de Coro. Venezuela

Marco Antonio González-Neira; Edwin Joselito Vásquez-Erazo;

Gonzalo Iván Andrade-Mena

DOI $10.35381 / \mathrm{cm} . v 7 i 12.437$

\section{Implementación de la Gestión Estratégica de Talento Humano en el Instituto Ecuatoriano de Seguridad Social}

\section{Implementation of the Strategic Management of Human Talent in the Ecuadorian Institute of Social Security}

\author{
Marco Antonio González-Neira \\ marco.gonzalez.27@est.ucacue.edu.ec \\ Universidad Católica de Cuenca, Cuenca \\ Ecuador \\ https://orcid.org/0000-0002-2072-4976 \\ Edwin Joselito Vásquez-Erazo \\ evasqueze@ucacue.edu.ec \\ Universidad Católica de Cuenca, Cuenca \\ Ecuador \\ https://orcid.org/0000-0001-9817-6773 \\ Gonzalo Iván Andrade-Mena \\ gonzaloandrade@ucacue.edu.ec \\ Universidad Católica de Cuenca, Cuenca \\ Ecuador \\ https://orcid.org/0000-0003-2777-4260
}

Recibido: 01 de octubre de 2020

Aprobado: 15 de diciembre de 2020 


\title{
RESUMEN
}

El objetivo de esta investigación es proponer un modelo gestión estratégica del talento humano, a través de la elaboración de una plantilla óptima en la Institución, para el crecimiento y desarrollo integral del potencial individual y organizacional. El alcance de esta investigación fue de tipo descriptivo. Se pudo evidenciar que no existe una adecuada selección de personal y ni un modelo de capacitaciones que se aplique al personal y una falta de. El modelo de gestión estratégica planteado ayudará a mejorar las etapas de contratación, selección, incentivos y evaluación para poder cumplir a cabalidad los objetivos Institucionales.

Descriptores: Actitud laboral; gestión; dirección de proyecto. (Palabras tomadas del Tesauro UNESCO).

\begin{abstract}
The objective of this research is to propose a strategic management model for human talent, through the elaboration of an optimal staff in the Institution, for the integral growth and development of individual and organizational potential. The scope of this research was descriptive. It was possible to show that there is no adequate selection of personnel and no training model applied to personnel and a lack of. The proposed strategic management model will help improve the hiring, selection, incentives and evaluation stages in order to fully meet the Institutional objectives.
\end{abstract}

Descriptores: Work attitudes; management; project management. (Words taken from the UNESCO Thesaurus). 


\section{CIENCIAMATRIA}

Revista Interdisciplinaria de Humanidades, Educación, Ciencia y Tecnología

Año VII. Vol. VII. N¹2. Enero - Junio. 2021

Hecho el depósito de ley: pp201602FA4721

ISSN-L: 2542-3029; ISSN: 2610-802X

Universidad Nacional Experimental Francisco de Miranda (UNEFM). Santa Ana de Coro. Venezuela

Marco Antonio González-Neira; Edwin Joselito Vásquez-Erazo;

Gonzalo Iván Andrade-Mena

\section{INTRODUCCION}

De acuerdo a (Acosta. 2008), los diferentes panoramas por lo que atraviesa la humanidad, se pueden constatar tres aspectos resaltan por su importancia: la globalización, el permanente cambio del contexto y la valoración del conocimiento. La insaciable competencia existente en el panorama empresarial actual ha visualizado que las empresas y negocios tanto del sector privado como las públicas sean cada vez más competitivas. Un factor importante es el recurso humano; por ello es que en la actualidad se habla del capital intelectual, capital humano, potencial humano, haciendo relevante al hombre dentro de la organización, por eso siempre se habla de que el capital humano es el activo más importante que tiene una Empresa o Institución. No se puede hablar de ninguna actividad relacionada al trabajo sin asociarlo al elemento hombre. Como se ha venido dando en el transitar de la historia podemos observar cómo ha evolucionado la gestión de las organizaciones siendo actores principales a pesar de que la tecnología ha evolucionado de una forma impresionante ya que los procesos ahora están mecanizados y automatizados en casi todos los procesos productivos o de servicios, pero siempre están supervisados por el hombre.

Para (Werther \& Davis, 1991), la gestión de recursos humanos es la ciencia práctica que se ocupan de la naturaleza de las relaciones de empleo y del conjunto de decisiones, acciones y cuestiones vinculadas a dichas relaciones. Coinciden que esta se dio de la mezcla de algunas teorías como son la gestión científica, del trabajo social y de la psicología industrial, pudimos observar que durante la primera guerra que se dio una evolución de la gestión de los recursos humanos con en las áreas de la contratación, en la selección del rendimiento, la formación, la mejora de las calificaciones y el desarrollo Igualmente siguiendo el mismo pensamiento se han manifestado para (Jackson, 1997), definiendo a la gestión como la acción y efecto de gestionar. Tomando en consideración que gestionar como llegar a la obtención de un redito empresarial, considerando a las personas como los recursos activos de las que ponen en funcionamiento desarrollando y 


\section{CIENCIAMATRIA \\ Revista Interdisciplinaria de Humanidades, Educación, Ciencia y Tecnología \\ Año VII. Vol. VII. N¹2. Enero - Junio. 2021 \\ Hecho el depósito de ley: pp201602FA4721 \\ ISSN-L: 2542-3029; ISSN: 2610-802X \\ Universidad Nacional Experimental Francisco de Miranda (UNEFM). Santa Ana de Coro. Venezuela \\ Marco Antonio González-Neira; Edwin Joselito Vásquez-Erazo; \\ Gonzalo Iván Andrade-Mena}

movilizando a las personas que una organización requiere para alcanzar sus metas y objetivos.

El Instituto Ecuatoriano de Seguridad Social (IESS) en los tiempos actuales no gestiona ni administra su talento humano como sistema integrado de individuos que se comprometen a conseguir objetivos comunes que vayan ligados a su misión y visión, esta situación altera de forma negativa en las relaciones laborales ante la carencia de una política coherente de recursos humanos que ha optado por no abordar directamente este tema de iniquidad y desigualdad laboral dentro de la institución. Razón por la cual no se puede visibilizar una espontánea manifestación de entrega, creatividad, motivación, disciplina, liderazgo, y espíritu de compromiso de unos con otros los altos funcionario saben de esta problemática que afecta a las organizaciones y tiene la solución en sus manos, pero tardan demasiado en tomar una decisión.

La Implementación de la Gestión Estratégica de Talento Humano en el Instituto Ecuatoriano de Seguridad Social, en los últimos años se ha visto limitada por la selección del personal contratado, ya que no se lo realiza de manera técnica a través de los procesos de reclutamiento y selección que logran identificar al personal idóneo para cada puesto especifico requerido

El objetivo de esta investigación es proponer un Modelo Gestión Estratégica del talento humano, a través de la elaboración de una Plantilla Optima en la Institución, para el crecimiento y desarrollo integral del potencial individual y organizacional.

\section{Referencial Teórico.}

\section{Evolución y aporte de la Gestión estratégica de recursos humanos.}

Para poder hablar de una gestión estratégica de talento humano se debe tener presente una buena mentalidad en lo referente, como bien lo plantean los autores (Michaels, et al., 2003) en su libro La guerra por el talento "...Tiene que ver con la manera como lo concebimos, con una apasionada creencia en que para alcanzar las aspiraciones de la 


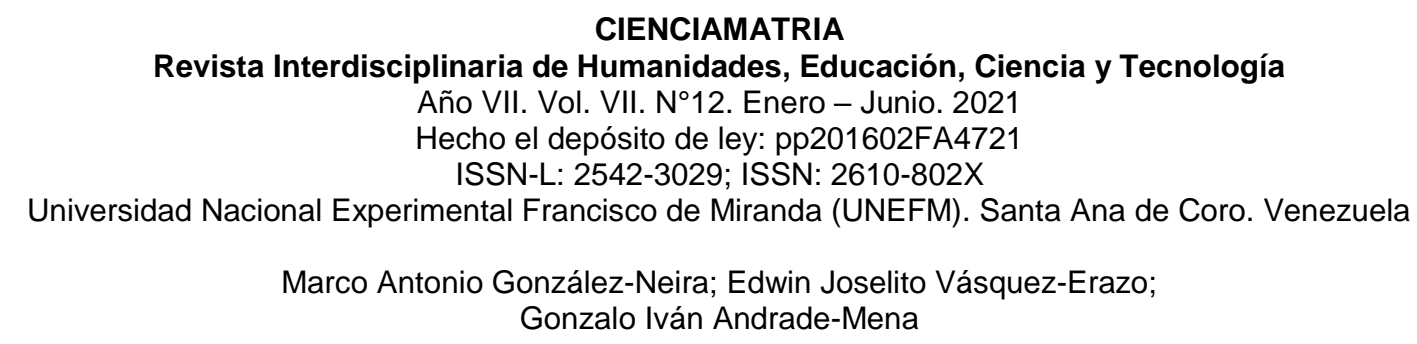

empresa uno tiene que contar con grandes talentos y que para atraer a los mejores es preciso que los líderes de la compañía se comprometan con esa meta." Para ellos debemos considerar contar con extraordinarios talentos que implica que las empresas y organizaciones trabajen con una diferente visión relacionada al personal sin que los vean como recursos sustituibles.

Al llevar a cabo este aspecto implica contar con una dinámica entusiasta, que nos ayude a identificar sus capacidades, habilidades e intereses personales para de esta manera poder mejorar sustancialmente y de manera innovadora las exigencias y objetivos de las empresas. Si tratamos el tema del cambio estas deben mejorar los aspectos cómo la formación del personal en cada una de sus áreas capacitándoles continuamente y brindándoles excelentes oportunidades de mejora (Mendieta-Ortega, et al., 2020).

En la actualidad, el recurso humano, denominado talento, se ha transformado en un eje vital para la consecución de objetivos de las organizaciones, ya sean públicas o privadas. Al realizar procesos de gestión en dicha área, se obtendrán varios beneficios tales como mejoramiento de calidad, aumento de beneficios para el cliente o usuario y una mejor percepción que tiene el mismo sobre la organización. Así lo demuestran investigaciones actuales aseguran que el éxito de las organizaciones radica en una adecuada "gestión de talento humano con un enfoque estratégico, mostrando el camino a realizar (...) con el trabajo eficaz de su gente, permite el logro de las metas trazadas" (Ramírez, et al., 2018).

Se menciona que tanto la planificación como la gestión estratégica son recursos que son puestos en marcha por las organizaciones, con el fin de optimizar la eficacia de los empleados, integrando los objetivos de cada trabajador con los que tiene la empresa, de manera que todas las partes se beneficien de los mencionados procesos de gestión. Entre los beneficios principales se tiene la definición de metas a corto, mediano y largo plazo, asimismo se establecen las competencias para cada puesto y las operaciones que se deben de realizar (Mendoza, et al., 2016). 


\section{CIENCIAMATRIA \\ Revista Interdisciplinaria de Humanidades, Educación, Ciencia y Tecnología \\ Año VII. Vol. VII. N¹2. Enero - Junio. 2021 \\ Hecho el depósito de ley: pp201602FA4721 \\ ISSN-L: 2542-3029; ISSN: 2610-802X \\ Universidad Nacional Experimental Francisco de Miranda (UNEFM). Santa Ana de Coro. Venezuela}

Marco Antonio González-Neira; Edwin Joselito Vásquez-Erazo;

Gonzalo Iván Andrade-Mena

En ese sentido, se asegura que varios cambios surgieron en las últimas décadas, debido a los avances tecnológicos, comunicacionales, así como los niveles educativos de los empleados. Del mismo modo, una competitividad empresarial en aumento, tanto a nivel público como privado, hace que la capacidad de respuesta que tenga el personal de una organización para con las demandas de los usuarios, van a depender del talento humano con el que se cuenta (López, et al., 2018).

No obstante, la gestión de los recursos humanos generalmente se la realiza a medida que avanza el tiempo de vida de la organización, es por ello que se suelen encontrar "roles pre estratégicos de la gestión de recursos humanos" (López, et al., 2018). Dichos roles, hacen referencia a actividades básicas que realizaban los empleados del departamento de recursos humanos, tales como la verificación del conteo de horas, recortes de personal, rendimiento, contrataciones, entre otros, que si bien, resultan ser actividades que aportan valor a la organización, no incluyen estrategias de gestión quedando disfrazada la función estratégica de dicho departamento y provocando a su vez, sentimientos de frustración, desilusión y desmotivación en los trabajadores que laboran en áreas administrativas, donde generalmente, sus actividades son rutinarias y repetitivas (Lema, et al. 2019).

En otras palabras, el personal de recursos humanos no aporta, de acuerdo con estos roles, una formulación de estrategias para los demás departamentos, sino que se limita a socializar entre los trabajadores y revisar su implementación (López, et al., 2018).

Sin embargo, en años recientes se ha podido constatar un aporte significativo por parte del departamento de recursos humanos para la formulación de estrategias, obteniendo un rol más participativo en la toma de decisiones de gestión. Sin embargo, cabe mencionar que para una adecuada implementación de estrategias administrativas y de gestión, los empleados deben de cumplir con ciertos criterios, destrezas, motivaciones y conocimiento, lo cual representa todo un reto y consolida el paso de una pre-estrategia a una gestión estratégica (López, et al., 2018). 


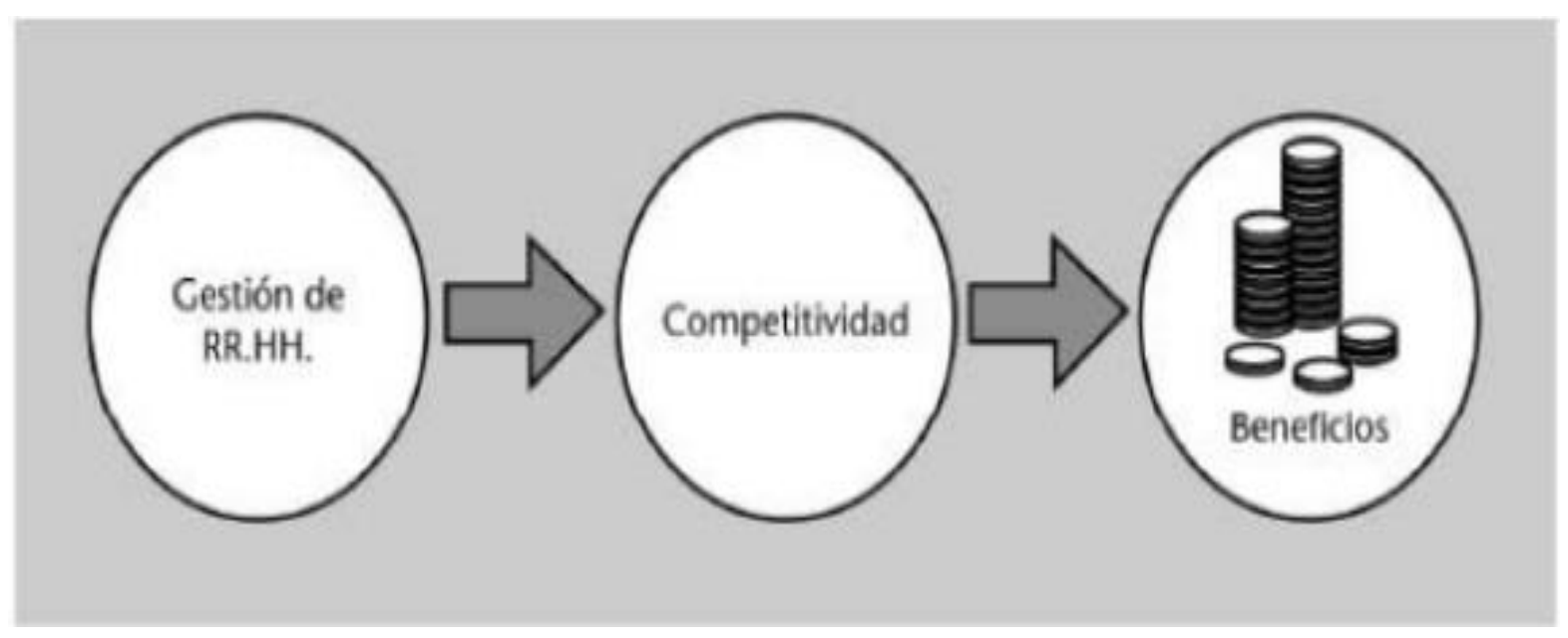

Figura 1. Resultado de una gestión adecuada de talento humano. Fuente: Rodríguez-Serrano (2004).

En el mismo contexto, toda organización en la actualidad pasa por innovaciones profundas en periodos de tiempo relativamente cortos, por lo que el proceso de adaptación por parte del personal que labora en dichas organizaciones debe ser constante, generando estrategias de gestión que puedan ser capaces de mantener y sostener a la empresa en un futuro inmediato. En ese sentido, se debe tomar en consideración áreas como la financiera, servicio y atención a clientes, procesos internos y los recursos humanos, siendo la última, la más importante para la consecución de las tres primeras (Boada-Grau \& Gil-Ripoll, 2009).

\section{Comportamiento de la Gestión estratégica de talento humano en Latinoamérica}

En varios países latinoamericanos ya se vienen implementando desde hace varios años atrás, diferentes procesos de gestión estratégica para el talento humano, los cuales realizan un seguimiento del personal, establecen indicadores y políticas compensatorias, para influir motivacionalmente en los empleados, con el fin de cumplir objetivos. Tal es el caso de Colombia, en donde las regulaciones implementadas se acoplan a las características socioculturales y políticas del país (Ramírez, et al., 2018). 
Se debe tomar en cuenta que, para una adecuada gestión estratégica del talento humano, es necesario sincronizar tareas, técnicas y equipos, con el fin de optimizar los recursos, colocando a los empleados en los puestos más aptos, en el momento adecuado, tomando en consideración sus destrezas y conocimientos y así cumplir los objetivos organizacionales (Rodríguez-Serrano, 2004). No obstante, a pesar de que estos elementos deben estar integrados, también se debe asegurar su interdependencia, como se visualiza a continuación:

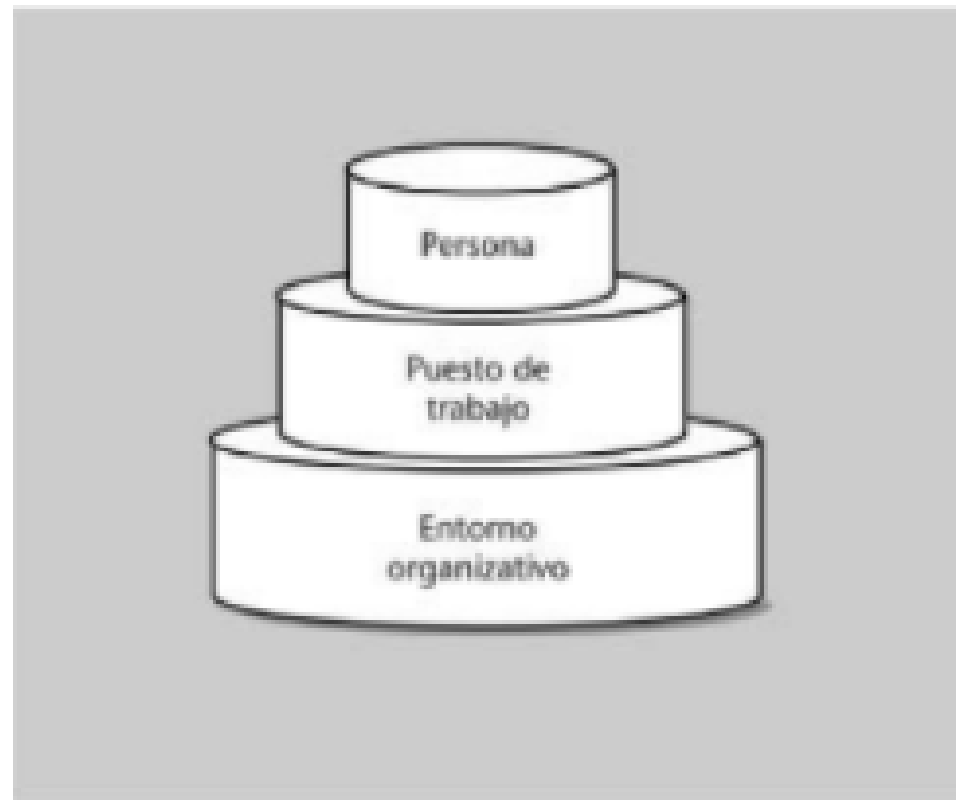

Figura 2. Elementos principales a considerar para una gestión estratégica de recursos humanos.

Fuente: Rodríguez-Serrano (2004).

Como se puede observar, el talento humano se debe acoplar al cargo para el cual fue contratado y, así mismo, el puesto de trabajo debe estar alineado con el entorno de la organización. En ese sentido una gestión estratégica eficaz, será la que permita que todo el engranaje funcione de manera óptima. Además, de acuerdo con la investigación planteada por (Boada-Grau \& Gil-Ripoll, 2009). 


\section{CIENCIAMATRIA \\ Revista Interdisciplinaria de Humanidades, Educación, Ciencia y Tecnología \\ Año VII. Vol. VII. N¹2. Enero - Junio. 2021 \\ Hecho el depósito de ley: pp201602FA4721 \\ ISSN-L: 2542-3029; ISSN: 2610-802X \\ Universidad Nacional Experimental Francisco de Miranda (UNEFM). Santa Ana de Coro. Venezuela \\ Marco Antonio González-Neira; Edwin Joselito Vásquez-Erazo; \\ Gonzalo Iván Andrade-Mena}

\section{Áreas fundamentales de la gestión estratégica de talento humano.}

Los Valores y Cultura hace referencia a la cultura organizacional y se considera "una herramienta estratégica para el éxito de la misma" (Rodríguez \& Romo, 2013). Así pues, se considera a la cultura como al conjunto de normas, creencias y valores que influye de manera directa por medio de la interacción entre los trabajadores. En ese sentido, el nivel de cultura organizacional puede ser fuerte o débil, dependiendo de la estrategia que tomen tanto directivos como el departamento de talento humano (Rodríguez \& Romo, 2013).

Por lo tanto, no se puede menospreciar este apartado, ya que se convierte en parte de la identidad empresarial, suscitando un criterio de pertenencia a cada empleado, provocando un cumplimiento de normas, políticas y procedimientos, principalmente. Gracias a esto, las organizaciones pueden adaptarse a su entorno, estandarizando la manera de interrelación tanto a nivel interno como externo, lo cual genera una imagen consolidada organizacional (Rodríguez \& Romo, 2013).

Los Puestos de trabajo en el sector público, a nivel internacional se los denominan como función pública o servicio civil y en el país se lo denomina de acuerdo a la última constitución como servicio público. En ese sentido, las dos partes, el contratante (organización pública) y el contratado, aceptan de manera voluntaria los términos de un contrato en donde se especifican las actividades que debe de realizar el futuro empleado en su puesto de trabajo, y por otra parte, se indica los deberes que tiene la organización a manera de compensación (Torres, et al. 2017).

Asimismo, en años recientes, los puestos de trabajo en el sector público se rigen principalmente por la Ley Orgánica del Servicio Público (LOSEP) y por el código de trabajo. En cuanto a la primera, es la encargada de regular los procesos de ingreso y promoción, carga remuneratoria, entre otros. Por su parte, el código de trabajo se encuentra la reglamentación sobre los requisitos para la contratación del personal, obligaciones, derechos y deberes de ambas partes (Torres, et al., 2017). 


\section{CIENCIAMATRIA \\ Revista Interdisciplinaria de Humanidades, Educación, Ciencia y Tecnología \\ Año VII. Vol. VII. N¹2. Enero - Junio. 2021 \\ Hecho el depósito de ley: pp201602FA4721 \\ ISSN-L: 2542-3029; ISSN: 2610-802X \\ Universidad Nacional Experimental Francisco de Miranda (UNEFM). Santa Ana de Coro. Venezuela}

Marco Antonio González-Neira; Edwin Joselito Vásquez-Erazo;

Gonzalo Iván Andrade-Mena

Comunicación interna es uno de los mayores inconvenientes de mayor preocupación por los que atraviesan las organizaciones públicas, radica en los inadecuados procesos de comunicación interna, así como una mínima percepción real acerca del clima organizacional (Álvarez, et al., 2020). En ese sentido, una gestión estratégica enfocada a la comunicación interna de toda organización pública "debe responder al mundo actual cambiante y competitivo con un nivel de comunicación sistémica e interactiva, capaz de escuchar a sus colaboradores buscando transmitir igualdad, horizontalidad; sensaciones que motiven a comunicar y relacionarse" (Charry, 2018, pág. 1). Por lo tanto, para evitar una mala comprensión de mensajes, informalidad e incluso rumores, directivos deben de realizar las gestiones necesarias para consolidar procesos de comunicación formal, a través de canales eficientes, oficiales y consolidados (Charry, 2018).

Si bien en cierto, en la actualidad existen canales de comunicación empresarial que se pueden conseguir de manera gratuita en internet, para el caso de empresas estatales es de vital importancia que se invierta en sistemas de comunicación seguros con el fin de evitar pérdidas o incluso hurtos de información que puede ser de alta importancia, y por otra parte, se logrará conseguir una serie de beneficios que si bien es cierto no son tangibles, generará identidad, sentido de pertenencia, participación y organización (Charry, 2018).

Para ello, no es suficiente con la adquisición de dichos sistemas, una gestión eficiente en los procesos de comunicación requiere de una planificación previa, puesto que cada organización es un ambiente diferente, ya sea por el número de empleados, tamaño, número de departamentos, funciones, entre otros. Al ser un elemento de vital importancia, los directivos de la organización deben de incluir a la comunicación interna dentro de sus políticas institucionales, de manera que se los empleados sientan mayor confianza y motivación para transmitir información de manera pertinente (Charry, 2018).

La Formación es una de las más grandes preocupaciones de los empleados que laboran en instituciones públicas no es un tema reciente, hace más de veinte años ya existía el 


\section{CIENCIAMATRIA \\ Revista Interdisciplinaria de Humanidades, Educación, Ciencia y Tecnología \\ Año VII. Vol. VII. N¹2. Enero - Junio. 2021 \\ Hecho el depósito de ley: pp201602FA4721 \\ ISSN-L: 2542-3029; ISSN: 2610-802X \\ Universidad Nacional Experimental Francisco de Miranda (UNEFM). Santa Ana de Coro. Venezuela}

Marco Antonio González-Neira; Edwin Joselito Vásquez-Erazo;

Gonzalo Iván Andrade-Mena

interés por la formación de funcionarios de las diferentes entidades públicas, y en ese sentido, los principales factores a formar radican en el cumplimiento eficaz y eficiente de sus funciones, capacidad de colaboración y trabajo en equipo, el trato a las personas que requieren de sus servicios y una ética intachable. Dichas cualidades, además de la formación académica pertinente, afianzará la capacidad de respuesta que tenga la entidad pública para con los ciudadanos (Beltrán, 1997). No obstante, según (Del-Campo \& Hernández, 2016) a pesar de los procesos de cambios sociales y avances en el sector público, en general, los países latinoamericanos:

Siguen caracterizándose por la baja capacidad técnica de sus burocracias. La falta de coherencia entre los recursos humanos disponibles y los necesarios para alcanzar metas de política pública hace que la creación y captación del recurso humano en los sectores públicos sea un problema de mucha importancia para todas las naciones de la región. (p. 167).

En Ecuador, el índice de desarrollo burocrático pasó del 15\% en el 2004 al $21 \%$ en el 2013, lo cual, si bien es cierto que la finalidad radica en mejorar y agilizar los procesos que deben de cumplir los ciudadanos, en la vida real, los niveles de autonomía, capacidad administrativa, procesos de mérito y oposición, resultan en deficientes o con problemas de transparencia. Cabe mencionar que, la Presidencia de la República, mediante el Instituto de Altos Estudios Nacionales, promueve procesos de formación y superior para funcionarios públicos de diferentes dependencias (Del-Campo \& Hernández, 2016).

La evaluación, desempeño y rendimiento es un proceso fundamental para corroborar el nivel de rendimiento del personal público es la evaluación, la cual debe constituir un sistema eficiente que permita medir el grado de una actividad realizada y su valor agregado para los procesos públicos (Vázquez-Martínez, et al., 2020). Lastimosamente, si se compara estos procesos con los que se realizan en las empresas privadas, las valoraciones obtenidas suelen ser negativas e insatisfactorias (Longo, 2005). A continuación, se indica un sistema integrado de la gestión de recursos humanos, donde la evaluación toma un rol protagónico: 
CIENCIAMATRIA

Revista Interdisciplinaria de Humanidades, Educación, Ciencia y Tecnología

Año VII. Vol. VII. N¹2. Enero - Junio. 2021

Hecho el depósito de ley: pp201602FA4721

ISSN-L: 2542-3029; ISSN: 2610-802X

Universidad Nacional Experimental Francisco de Miranda (UNEFM). Santa Ana de Coro. Venezuela

Marco Antonio González-Neira; Edwin Joselito Vásquez-Erazo;

Gonzalo Iván Andrade-Mena

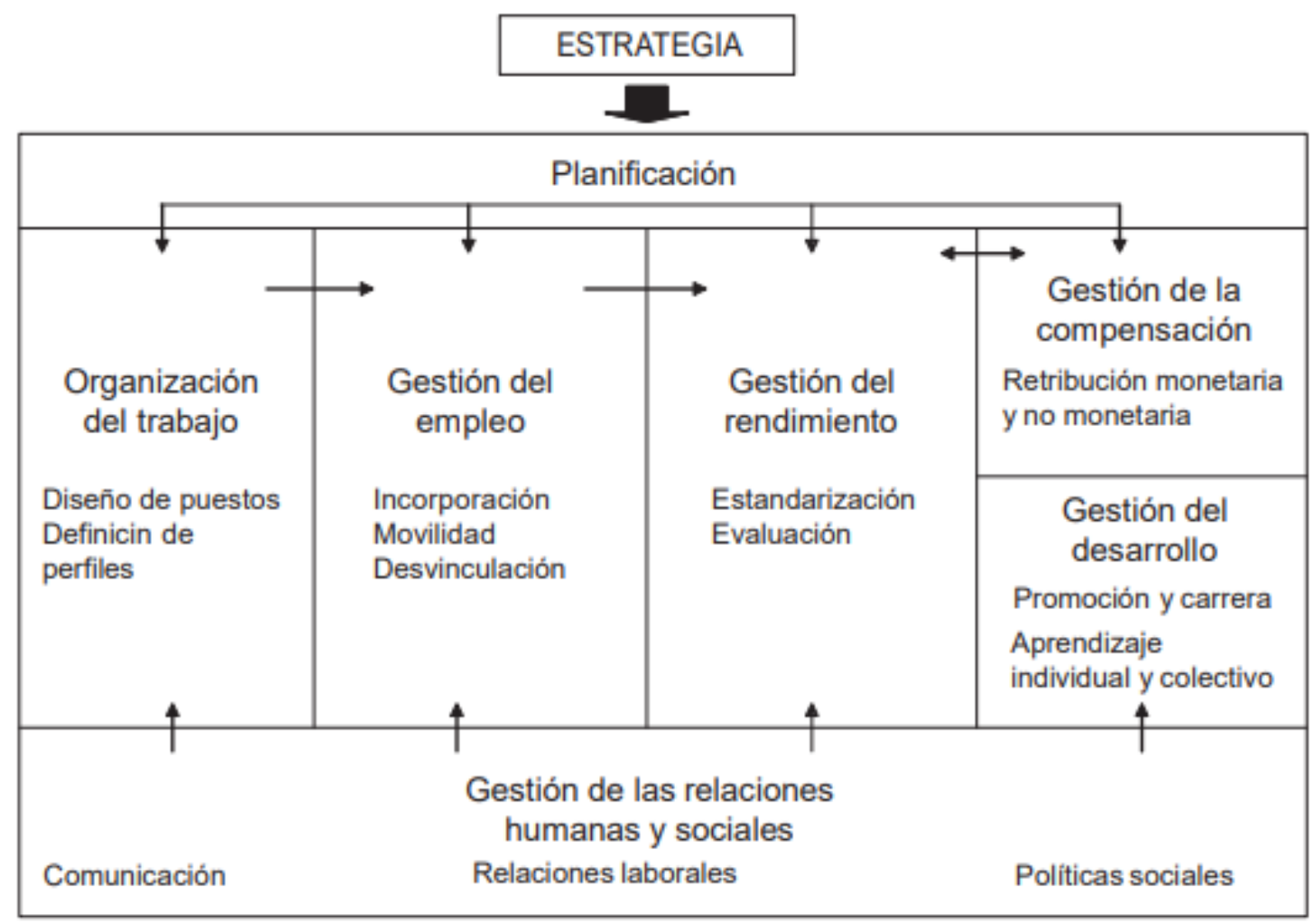

Figura 3. Sistema de gestión de recursos humanos.

Fuente: Longo (2005).

En ese sentido, se han identificado fallos recurrentes que comete la gestión pública en las evaluaciones del desempeño del personal, entre los que se tiene al objeto de evaluación, el rol de los evaluadores, que no suelen estar capacitados para dichas tareas, evitar conflictos con compañeros de trabajo, una deficiente política de los sistemas de evaluación obligatoria (Longo, 2005).

Por lo tanto, un factor predominante en los procesos de evaluación de desempeño radica en los administradores de turno, puesto que, suelen cambiar luego de un periodo de tiempo relativamente corto, por lo que, al llegar una persona nueva al cargo, bien podría modificar los procesos ya establecidos por la administración anterior, provocando cierta incertidumbre e incomodidad a los empleados. Sin embargo, las reestructuraciones 


\section{CIENCIAMATRIA \\ Revista Interdisciplinaria de Humanidades, Educación, Ciencia y Tecnología \\ Año VII. Vol. VII. N¹2. Enero - Junio. 2021 \\ Hecho el depósito de ley: pp201602FA4721 \\ ISSN-L: 2542-3029; ISSN: 2610-802X \\ Universidad Nacional Experimental Francisco de Miranda (UNEFM). Santa Ana de Coro. Venezuela \\ Marco Antonio González-Neira; Edwin Joselito Vásquez-Erazo; \\ Gonzalo Iván Andrade-Mena}

tienen como objetivo principal de optimizar el rendimiento de los empleados públicos y, por ende, de la institución en la que se desempeñan, ofreciendo así una mejor atención a los trámites públicos para los ciudadanos, generando mayor aceptación (Pablos \& Biedma, 2013).

La Selección del personal en el Ecuador se lleva a través de varios procesos de selección de personal para instituciones públicas, en teoría, se encuentran direccionados de manera transparente, no obstante "los concursos por meritocracia de mérito y oposición se encuentran si elementos importantes, lo que genera una solo idea entre los concursantes que estos ya se encuentran "ganados" (Vargas \& Quishpe, 2019). Dichos procesos se encuentran dentro de la ley, que en la realidad no se suele cumplir en su totalidad, provocado principalmente por índices altos de corrupción (Argudo, et al., 2019). Dentro de los pasos para la selección de personal, mencionan al reclutamiento a través de la prensa, redes sociales y por la página Red Socio Empleo, principalmente; a continuación, se realiza la constatación de lo descrito en el Curriculum vitae, las correspondientes pruebas de carácter psicotécnicas y evaluaciones de conocimiento; posteriormente se valora los méritos del aspirante y finalmente, la entrevista (Vargas \& Quishpe, 2019).

La Retribución salarial en la entidad encargada de regular y gestionar los sueldos y salarios de los empleados públicos, es el Estado, el cual, de acuerdo a su planeación por parte del Ministerio correspondiente, fija los salarios para cada empleado, de acuerdo al puesto y dependencia que ocupe. En ese sentido, en los últimos años, la política latinoamericana ha puesto énfasis en fortalecer las dependencias públicas, en ese sentido, se ha observado un excedente en el personal público y unas "burocracias infladas" (Carrillo \& Vásconez, 2011, p. 2). No obstante, también se ha podido visualizar que, en algunas dependencias, existen colaboradores que reciben salarios altos, lo cual en algunos casos se ve contrarrestado por el descontento por parte de los ciudadanos por una atención deficiente (Valencia, et al., 2019). 


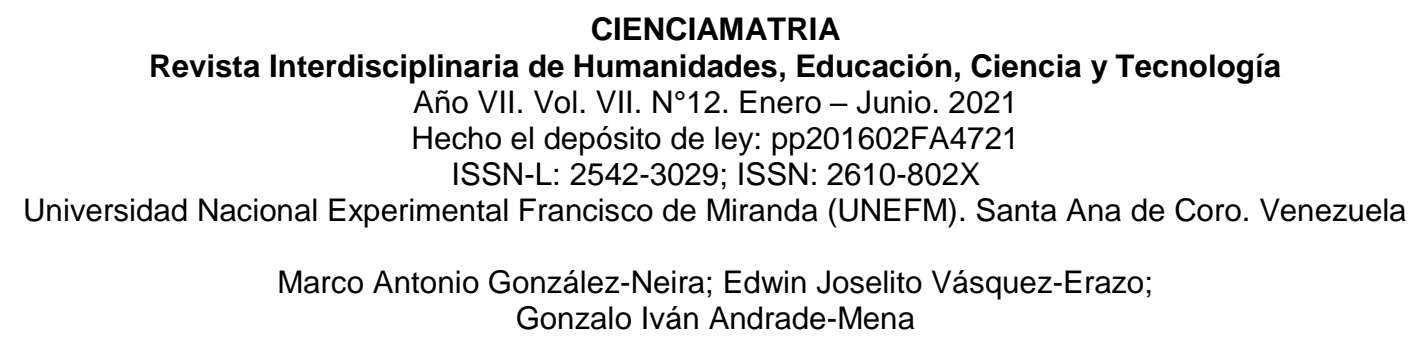

El Clima y motivación tomando como referencia a una entidad pública ecuatoriana, el $84 \%$ de los trabajadores públicos reconocen que el clima organizacional si incide en el desempeño laboral, resultando evidente que la mayoría de los trabajadores públicos reconocen la relevancia que tiene el clima laboral en el normal desenvolvimiento de actividades diarias dentro de la institución (Jiménez \& Mosquera, 2017).

La motivación laboral viene definida por una serie de elementos internos y externos tales como la falta de reconocimiento, el estado del área física de labores, malas relaciones interpersonales, ausencia de programas de capacitación, lo cual podría provocar que el trabajador se sienta desmotivado para laboral de manera eficiente. Por otra parte, y debido a deficientes relaciones sociales, provocada por intereses personales o grupales, la tensión que pueden pasar los empleados durante sus jornadas laborales constituye un riesgo alto (Macas \& Solís, 2019).

\section{MÉTODO.}

La investigación se desarrolló desde una metodología descriptiva con diseño no experimental transversal, lo cual permitió recopilar la información en único momento, sin ser manipulada deliberadamente, sino, descrita tal como ocurre en la realidad, en una población conformada por 17 funcionarios del Instituto Ecuatoriano de Seguridad Social, se sede Cuenca, Provincia de Azuay, siendo encuestados mediante muestreo por conveniencia y cuestionario dicotómico, siendo validado por juicio de expertos y coeficiente Kuder-Richarson-20, obteniéndose un resultado de 0,87 considerándose confiable para ser aplicado, analizándose los resultados a partir de la estadística descriptiva. 


\section{CIENCIAMATRIA}

Revista Interdisciplinaria de Humanidades, Educación, Ciencia y Tecnología

Año VII. Vol. VII. N¹2. Enero - Junio. 2021

Hecho el depósito de ley: pp201602FA4721

ISSN-L: 2542-3029; ISSN: 2610-802X

Universidad Nacional Experimental Francisco de Miranda (UNEFM). Santa Ana de Coro. Venezuela

Marco Antonio González-Neira; Edwin Joselito Vásquez-Erazo;

Gonzalo Iván Andrade-Mena

\section{RESULTADOS}

Podemos decir que esta investigación, parte de los resultados de la encuesta, que se les realizó al personal tanto del código de trabajo como a los de la LOSEP del IESS Cañar en lo concerniente a las actividades laborales que desempeñan cada uno de los funcionarios encuestados, para ello vamos a resumir en dimensiones.

Dimensión: Desarrollo de actividades para estas preguntas el $88,2 \%$ de funcionarios encuestados, dan a conocer, que no están de acorde a su perfil académico con el mismo porcentaje de los que no están realizando las actividades por las que fueron contratados.

En lo referente a los incentivos laborales podemos observar que la gran mayoría de los encuestados sienten una inconformidad en este tema, ya que el porcentaje es de $94,10 \%$ como podemos observar en la siguiente figura.

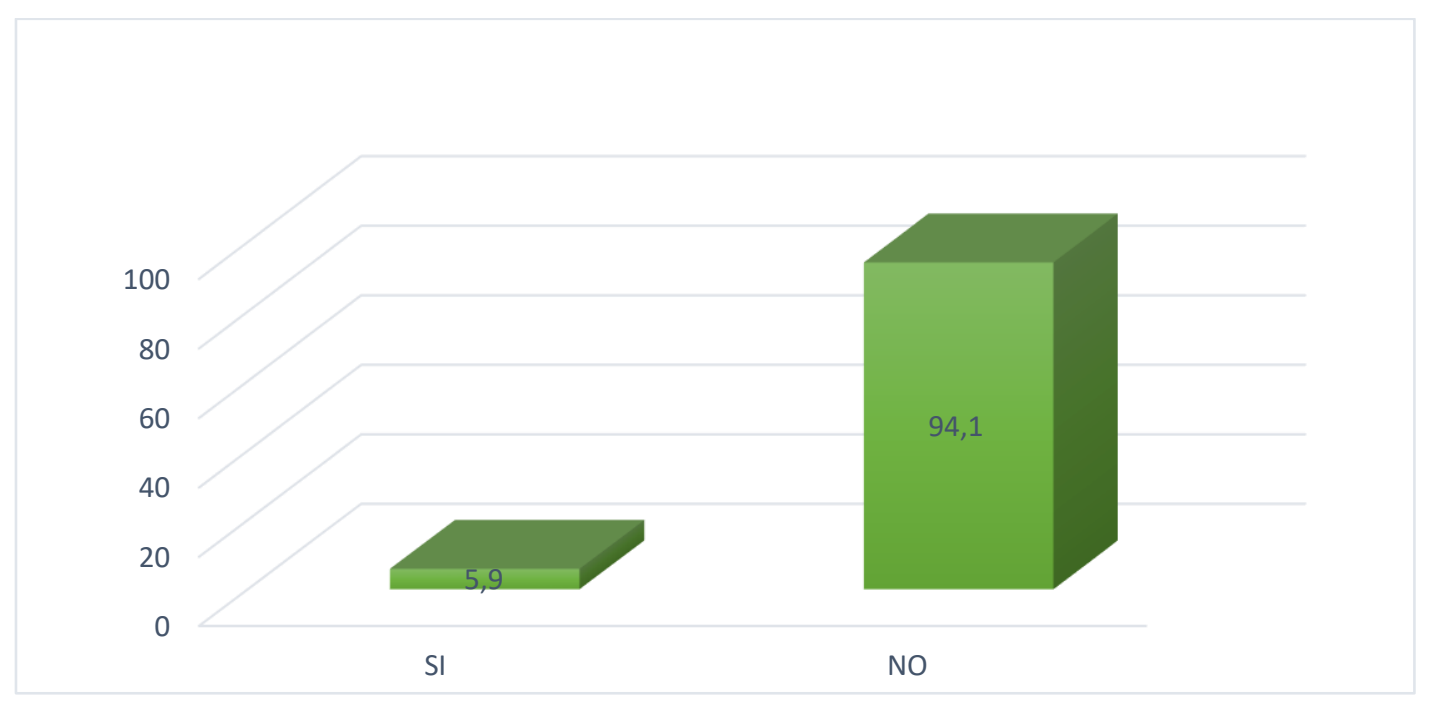

Figura 4. Incentivos laborales.

En cuanto a la existencia de una plantilla óptima dentro de la Institución casi más de la mitad de los encuestados afirman que no se cuenta con dicha plantilla y que se ubica al personal sin contar con el análisis respectivo. 


\section{CIENCIAMATRIA}

Revista Interdisciplinaria de Humanidades, Educación, Ciencia y Tecnología

Año VII. Vol. VII. N¹2. Enero - Junio. 2021

Hecho el depósito de ley: pp201602FA4721 ISSN-L: 2542-3029; ISSN: 2610-802X

Universidad Nacional Experimental Francisco de Miranda (UNEFM). Santa Ana de Coro. Venezuela

Marco Antonio González-Neira; Edwin Joselito Vásquez-Erazo;

Gonzalo Iván Andrade-Mena

Con respecto a la pregunta que si se realiza evaluaciones dentro de la institución la establecimos en algunas opciones como trimestralmente, semestralmente, anualmente 0 nunca, gran parte de los funcionarios afirmaron que si se realiza una evaluación anualmente con un porcentaje del $70,60 \%$.

Para la pregunta sobre el clima laboral si este influye en su desenvolvimiento dentro de la Institución una mayoría de los funcionarios encuestados contestaron en un $87.5 \%$ que si influyen en su labor diaria.

En la pregunta que si existen preferencias por ideologías políticas dentro de la institución los funcionarios contestaron que si existe dichas preferencias en un porcentaje del $68,8 \%$. En cuanto a la pregunta que si consideran que se les está capacitando constantemente respondieron en un $58,8 \%$ que si se les está capacitando constantemente como se indica en la siguiente figura.

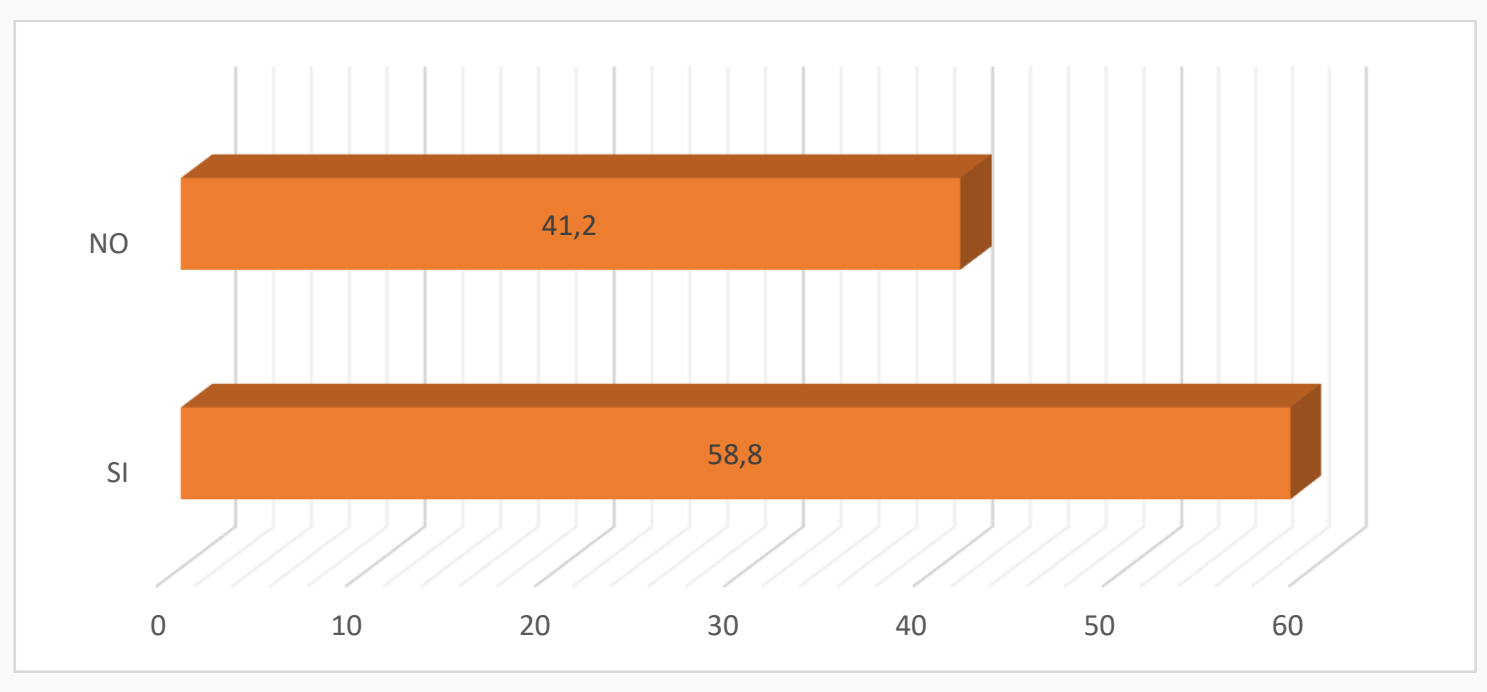

Figura 5. Capacitaciones. 


\section{CIENCIAMATRIA}

Revista Interdisciplinaria de Humanidades, Educación, Ciencia y Tecnología

Año VII. Vol. VII. N¹2. Enero - Junio. 2021

Hecho el depósito de ley: pp201602FA4721

ISSN-L: 2542-3029; ISSN: 2610-802X

Universidad Nacional Experimental Francisco de Miranda (UNEFM). Santa Ana de Coro. Venezuela

Marco Antonio González-Neira; Edwin Joselito Vásquez-Erazo;

Gonzalo Iván Andrade-Mena

\section{Esquema de la Propuesta de la Gestión Estratégica de Talento Humano en el IESS del Cañar}

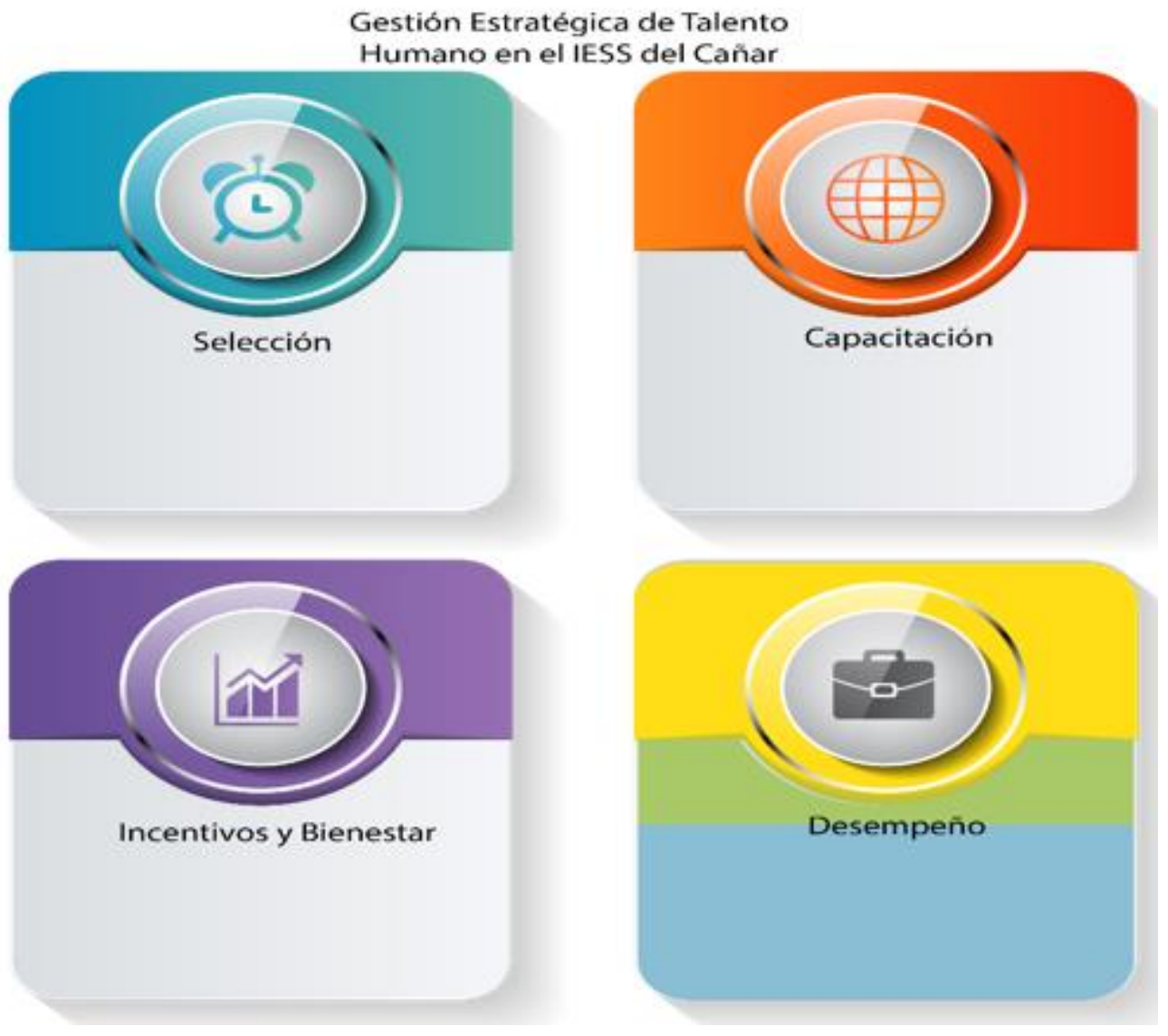

Figura 6. Esquema de la Propuesta de Gestión Estratégica de Talento Humano.

Los elementos del modelo propuesto de una Gestión Estratégica de Talento Humano los describimos como la selección del talento humano, la capacitación, los incentivos y el desempeño. A continuación, elaboraremos una descripción de los elementos más importantes que recoge la gestión de talento humano planteado en la presente investigación del IESS Cañar. 
CIENCIAMATRIA

Revista Interdisciplinaria de Humanidades, Educación, Ciencia y Tecnología

Año VII. Vol. VII. N¹2. Enero - Junio. 2021

Hecho el depósito de ley: pp201602FA4721

ISSN-L: 2542-3029; ISSN: 2610-802X

Universidad Nacional Experimental Francisco de Miranda (UNEFM). Santa Ana de Coro. Venezuela

Marco Antonio González-Neira; Edwin Joselito Vásquez-Erazo;

Gonzalo Iván Andrade-Mena

Para que tenga éxito una gestión de talento humano se debe contar con un personal idóneo en cada área para poder cumplir los objetivos estratégicos de la institución.

Comenzamos identificando las necesidades más importantes de acuerdo a lo que requiere la Institución para poder establecer el perfil del candidato, este debe cumplir con los requisitos básicos de conocimientos y experiencia que el puesto exija.

La Convocatoria se la debe realizar por los medios más conocidos de la localidad así como por la página web de la Institución para que exista la mayor transparencia posible. Al llegar a esta etapa de selección los postulantes tienen que rendir una prueba profesional y luego de ello se realiza una entrevista con los aspirantes que tengas las notas más altas.

Finalmente llegamos a la contratación que es donde se escoge al candidato mejor puntuado y se procede a realizar su contrato.

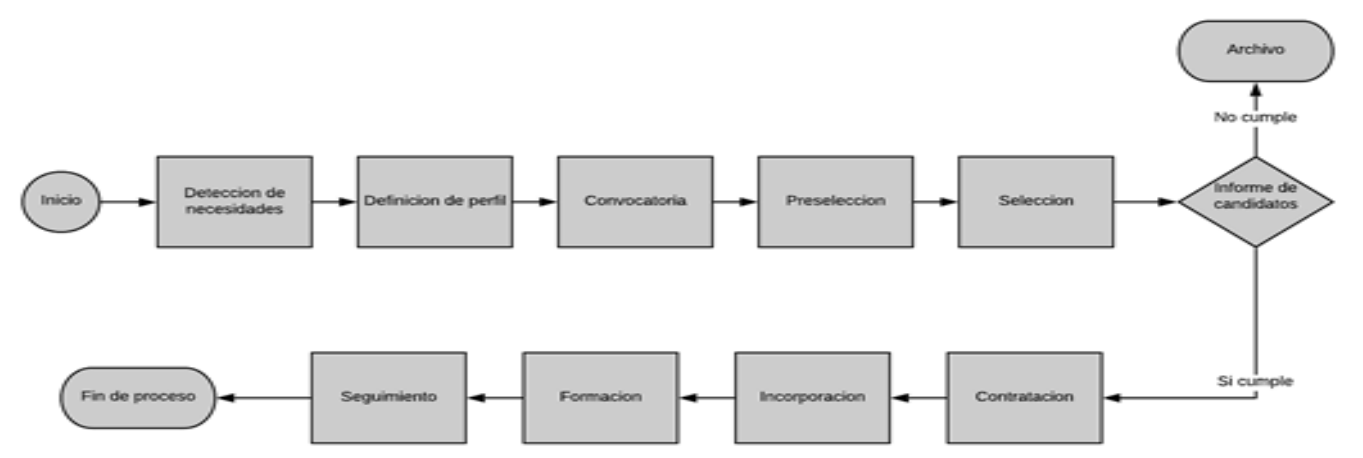

Figura 7. Proceso de selección y contratación de personal.

Fuente: Lema, et al. (2019). 


\section{CIENCIAMATRIA}

Revista Interdisciplinaria de Humanidades, Educación, Ciencia y Tecnología

Año VII. Vol. VII. N¹2. Enero - Junio. 2021

Hecho el depósito de ley: pp201602FA4721

ISSN-L: 2542-3029; ISSN: 2610-802X

Universidad Nacional Experimental Francisco de Miranda (UNEFM). Santa Ana de Coro. Venezuela

Marco Antonio González-Neira; Edwin Joselito Vásquez-Erazo;

Gonzalo Iván Andrade-Mena

La capacitación dentro de la Institución se la debería realizar a todos los funcionarios ya sean estos de la LOSEP y del Código del Trabajo de acuerdo a las necesidades de sus puestos de trabajo para que estos conocimientos sean puestos en la práctica diaria.

Para ellos presentamos un plan de capacitación para que se pueda llegar a una óptima actualización de conocimientos y reforzar las destrezas de los servidores y trabajadores de la Institución, llegando con el mismo a brindar una atención de calidad y calidez que se merecen los afiliados y beneficiarios de la Seguridad Social .Con esta matriz de capacitación queremos dar cumplimiento estricto a la planificación de capacitaciones dentro del IESS Cañar, ya que todos los años nos presentan el plan anual de capacitaciones pero nunca se cumplen las fechas ni los temas planteados, ocasionando una frustración dentro de todo el personal (Lema, et al., 2019).

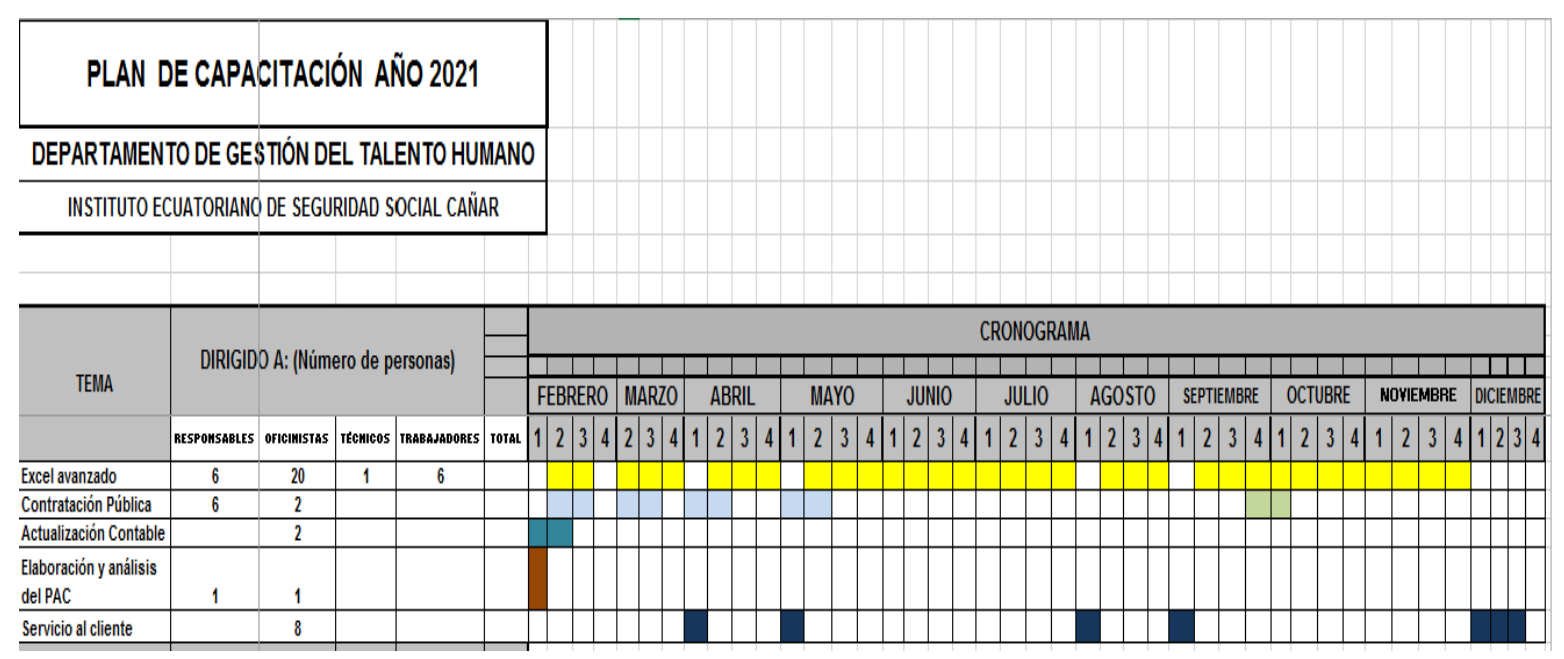

Figura 8. Proceso de capacitación al personal. 


\section{CIENCIAMATRIA \\ Revista Interdisciplinaria de Humanidades, Educación, Ciencia y Tecnología \\ Año VII. Vol. VII. N¹2. Enero - Junio. 2021 \\ Hecho el depósito de ley: pp201602FA4721 ISSN-L: 2542-3029; ISSN: 2610-802X \\ Universidad Nacional Experimental Francisco de Miranda (UNEFM). Santa Ana de Coro. Venezuela}

Marco Antonio González-Neira; Edwin Joselito Vásquez-Erazo;

Gonzalo Iván Andrade-Mena

Dentro del sector público específicamente en el IESS los Incentivos y Bienestar quedaron para los trabajadores del Código de Trabajo ya que de acuerdo al decreto Ejecutivo No. 1701 de 30 de abril de 2009 suscrito por el Presidente Rafael Correa Delgado, establece los criterios que sustentan la contratación colectiva en las instituciones públicas; $y$, donde se suprime y prohíbe cláusulas que contengan privilegios y beneficios exagerados que atentan contra el interés general todos los que pertenezcan al Código de trabajo como a los de la LOSEP, pero con Decreto Ejecutivo No. 225 de 18 de enero de 2010, se reforma el Decreto 1701, el 30 de abril de 2009, publicado en el Registro Oficial No. 592, del 18 de mayo de 2009, con el que se reintegran los derechos a los trabajadores amparados por el Código del Trabajo, sujeto a los límites establecidos por el Ministerio de Relaciones Laborales (Resolución DC 342 del Instituto Ecuatoriano De Seguridad Social, 2010) En cambio, los servidores públicos quedaron sin los privilegios que contaban antes, por lo que se debe establecer una figura en la que el personal se sienta incentivado y mejorado en su bienestar social por lo que se propone una matriz de incentivos.

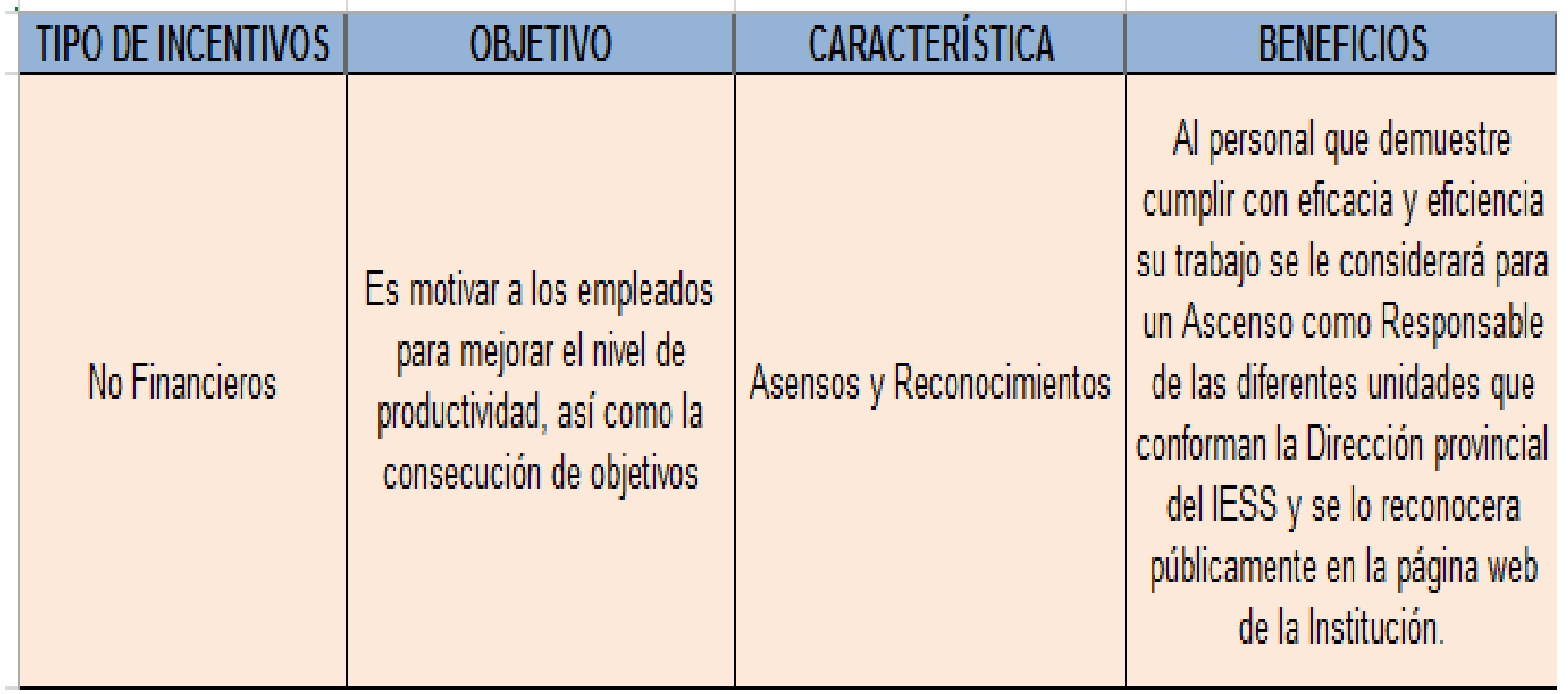

Figura 9. Plan de incentivos al personal.

Fuente: Lema, et al. (2019). 


\section{CIENCIAMATRIA \\ Revista Interdisciplinaria de Humanidades, Educación, Ciencia y Tecnología \\ Año VII. Vol. VII. N¹2. Enero - Junio. 2021 \\ Hecho el depósito de ley: pp201602FA4721 \\ ISSN-L: 2542-3029; ISSN: 2610-802X \\ Universidad Nacional Experimental Francisco de Miranda (UNEFM). Santa Ana de Coro. Venezuela}

Marco Antonio González-Neira; Edwin Joselito Vásquez-Erazo;

Gonzalo Iván Andrade-Mena

El desempeño de los empleados y trabajadores es considerado como la parte neurálgica para desenvolvimiento de la Institución, este sentido es indispensable evaluar su desempeño de acuerdo a sus competencias y a las actividades que realizan cada uno de ellos, por lo que sugerimos realizar una vez cada año la siguiente evaluación para poder observar donde pueden estar los posibles problemas en atención tanto a los usuarios internos como externos. (Robbins, 2004).

\begin{tabular}{|c|c|c|c|}
\hline \multirow{2}{*}{$\begin{array}{l}\text { DESTREZA } \\
Y \\
\text { HABILIDAD }\end{array}$} & \multicolumn{3}{|c|}{ EVALUACION DE DESEMPEÑO AL PERSONAL DEL IESS DEL CAÑAR } \\
\hline & ALTA & MEDIA & BAJA \\
\hline $\begin{array}{l}\text { Aprendizaje } \\
\text { continuo }\end{array}$ & Realiza trabajos de investigación que comparte con sus compañeros. & $\begin{array}{l}\text { Mantiene su formación técnica. Realiza un gran esfuerzo por } \\
\text { adquirir nuevas habilidades y conocimientos. }\end{array}$ & $\begin{array}{c}\text { Busca información sólo cuando la } \\
\text { necesita, lee manuales, libros y } \\
\text { otros, para aumentar sus }\end{array}$ \\
\hline $\begin{array}{c}\text { Conocimiento } \\
\text { del entrono } \\
\text { organizaciona }\end{array}$ & $\begin{array}{l}\text { Identifica las razones que motivan determinados comportamientos en } \\
\text { los grupos de trabajo. }\end{array}$ & $\begin{array}{l}\text { Identifica, describe y utiliza las relaciones de poder e } \\
\text { influencia existentes dentro de la institución. }\end{array}$ & $\begin{array}{l}\text { Utiliza las normas, la cadena de } \\
\text { mando y los procedimientos } \\
\text { establecidos para cumplir con sus }\end{array}$ \\
\hline $\begin{array}{c}\text { Relaciones } \\
\text { Humanas }\end{array}$ & $\begin{array}{l}\text { Construye relaciones beneficiosas para el usuario interno como } \\
\text { externo. }\end{array}$ & $\begin{array}{l}\begin{array}{l}\text { Establece un ambiente cordial con personas desconocidas, } \\
\text { desde el primer encuentro. }\end{array} \\
\end{array}$ & Entabla relaciones a nivel laboral. \\
\hline $\begin{array}{l}\text { Actitud al } \\
\text { Cambio }\end{array}$ & $\begin{array}{c}\text { Modifica las acciones para responder a los cambios organizacionales } \\
\text { o de prioridades. Propone mejoras para la organización. }\end{array}$ & $\begin{array}{c}\text { Modifica su comportamiento para adaptarse a la situación } 0 \\
\text { a las personas }\end{array}$ & $\begin{array}{l}\text { Aplica normas que dependen a cada } \\
\text { situación o procedimientos para } \\
\text { cumplir con sus responsabilidades. }\end{array}$ \\
\hline $\begin{array}{l}\text { Orientación a } \\
\text { los resultados }\end{array}$ & $\begin{array}{c}\text { Realiza las acciones necesarias para cumplir con las metas } \\
\text { propuestas. Desarrolla o modifica procesos organizacionales que } \\
\text { contribuyan a mejorar la eficiencia. }\end{array}$ & Modifica los métodos de trabajo para conseguir mejoras. & Realiza moderadamente su trabajo. \\
\hline $\begin{array}{l}\text { Orientación } \\
\text { de servicio }\end{array}$ & $\begin{array}{l}\text { Demuestra interés en atender a los usuarios internos o externos con } \\
\text { rapidez, diagnóstica correctamente la necesidad y plantea soluciones } \\
\text { adecuadas. }\end{array}$ & Identifica las necesidades del usuario interno o externo & $\begin{array}{l}\text { Actúa a partir de los requerimientos } \\
\text { de los usuarios ofreciendo } \\
\text { respuestas sin valor agregado }\end{array}$ \\
\hline $\begin{array}{l}\text { Juicio y toma } \\
\text { de decisiones }\end{array}$ & $\begin{array}{c}\text { Toma decisiones de complejidad alta sobre la base de la misión y } \\
\text { objetivos de la institución, y de la satisfacción del problema del usuario. }\end{array}$ & $\begin{array}{l}\text { Toma decisiones de complejidad media sobre la base de } \\
\text { sus conocimientos. }\end{array}$ & $\begin{array}{l}\text { Toma decisiones de complejidad } \\
\text { baja. }\end{array}$ \\
\hline
\end{tabular}

Figura 10. Plan de evaluación de desempeño.

Fuente: Ministerio del Trabajo (2014).

\section{CONCLUSIONES}

Finalizada la investigación, podemos concluir que en el IESS los funcionarios no se encuentran realizando las actividades por la que fueron contratados y tampoco tienen el perfil óptimo para hacer dichas actividades ocasionando que no brinden un servicio de calidad y calidez como exige la misión institucional.

Para ello se ha realizado un plan de capacitaciones que sin duda mejorará exponencialmente la atención del personal hacia el cliente externo como interno. 


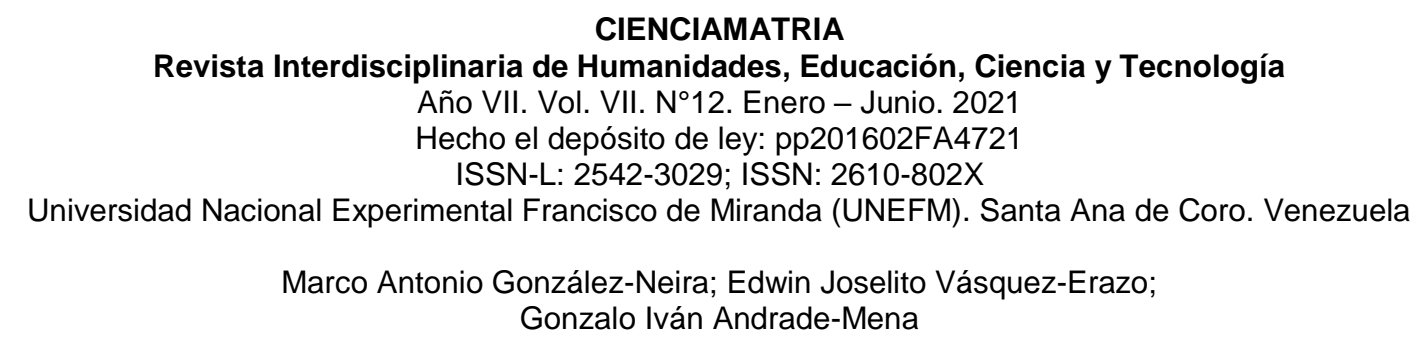

Con la implementación de una evaluación de desempeño adecuada a la realidad que viven los empleados y trabajadores se pretende que el personal este siempre actualizándose y para ellos se creó un mecanismo de incentivos que logre que tengan siempre una motivación para cumplir sus labores de forma efectiva que ayudará a los procesos de los objetivos tanto de la misión como de visión Institucional.

\section{REFERENCIAS CONSULTADAS}

Acosta, G. (2008). Gestión de Recursos Humanos en la Administración Tributaria Venezolana [Human Resources Management in the Venezuelan Tax Administration]. Observatorio Laboral Revista Venezolana, 1(2), 79-100.

Álvarez, C., Narváez, C., Erazo, J., \& Luna, K. (2020). Lógica difusa como herramienta de evaluación del portafolio de inversiones en el sector cooperativo del Ecuador [Fuzzy logic as an investment portfolio evaluation tool in Ecuador's cooperative sector] Revista Espacios, 41(36). Obtenido de https://n9.cl/bai6c

Argudo, K. J., Erazo, J. C., \& Narváez, C. I. (2019). Evaluación de Control Interno en Riesgos Estratégicos para la Dirección de Planificación de la Universidad de Cuenca[Evaluation of Internal Control in Strategic Risks for the Planning Department of the University of Cuenca]. Revista Arbitrada Interdisciplinaria Koinonía, 4(1), 67-96. http://dx.doi.org/10.35381/r.k.v4i1.372

Beltrán, M. (1997). La formación y los empleados públicos [Training and public employees]. Revista Reis n.77. pp. 51-68.

Boada-Grau, J., \& Gil-Ripoll, C. (2009). Gestión Estratégica de Recursos Humanos como Antecedente del Balanced Scorecard [Strategic Human Resource Management as a Background to the Balanced Scorecard]. Revista de Psicología del Trabajo y de las Oganizaciones, 25(2), 123-134.

Carrillo, P., \& Vásconez, V. (2011). La brecha salarial entre instituciones publicas en el Ecuador (An Approximation of the Wage Gap between Public Entities in Ecuador). SSRN Electronic Journal. https://dx.doi.org/10.2139/ssrn.1905781 
Charry, H. (2018). La gestión de la comunicación interna y el clima organización interna y el clima organizacional en el sector público [The management of internal communication and the internal organizational climate in the public sector]. Comunicación, 9(1), 25-34.

Del-Campo, E., \& Hernández, J. (2016). Talento para lo público: analizando los sistemas de formación y capacitación de funcionarios públicos en América Latina [Talent for the public: analyzing education and training systems for public officials in Latin America]. Revista del CLAD Reforma y Democracia, (64), 165-192.

Jackson, B. L. (1997). Enciclopedia del Management. Editorial Océano Centrum.

Jiménez, H., \& Mosquera, A. (2017). Clima organizacional y su incidencia en el desempeño laboral de los trabajadores, de los departamentos financieros en entidades públicas. https://n9.cl/kgc5j

Lema, P., Erazo, J., \& Narváez, C. (2019). El talento humano, factor clave para la gestión organizacional en Instituciones de intermediación financiera. Revista Arbitrada Interdisciplinaria Koinonía, 4(1), 349-375. http://dx.doi.org/10.35381/r.k.v4i1.461

Longo, F. (2005). Evaluación y gestión del rendimiento laboral en las administraciones públicas [Evaluation and management of work performance in public administrations]. Presupuesto y gasto público, 41, 127-144.

López, Á., Pasamar, S., \& Valle, R. (2018). Fundamentos para la gestión estratégica de los recursos humanos [Fundamentals of strategic human resource management]. Cataluña: Universistat Oberta de Catalunya.

Macas, A., \& Solís, M. (2019). Las relaciones interpersonales y su influencia en la motivación laboral de los colaboradores de instituciones públicas [Interpersonal relationships and their influence on the work motivation of employees of public institutions]. https://n9.cl/9zyh

Mendieta-Ortega, M. P., Erazo-Álvarez, J. C., \& Narváez-Zurita, C. I. (2020). Gestión por competencias: herramienta clave para el rendimiento laboral del talento humano del sector hospitalario [Management by competences: key tool for the labor performance of the human talent of the hospital sector]. Revista Arbitrada Interdisciplinaria Koinonía, 10(5), 287-312. http://dx.doi.org/10.35381/r.k.v5i10.696 


\section{CIENCIAMATRIA}

Revista Interdisciplinaria de Humanidades, Educación, Ciencia y Tecnología

Año VII. Vol. VII. N¹2. Enero - Junio. 2021

Hecho el depósito de ley: pp201602FA4721

ISSN-L: 2542-3029; ISSN: 2610-802X

Universidad Nacional Experimental Francisco de Miranda (UNEFM). Santa Ana de Coro. Venezuela

Marco Antonio González-Neira; Edwin Joselito Vásquez-Erazo;

Gonzalo Iván Andrade-Mena

Mendoza, D., López, D., \& Salas, E. (2016). Planificación estratégica de recursos humanos. Efectiva forma de identificar necesidades de personal [Strategic planning of human resources. Effective way to identify personnel needs]. Económicas CUC, 37(1), 63-80.

Michaels, E., Handfield, H., \& Axelrod, B. (2003). La guerra por el talento [The war for talent]. Madrid: Editorial Centro de Estudios Ramón Areces, S.A.

Ministerio del Trabajo. (2014). Gestión Evaluación de Desempeño. https://n9.cl/pefbw

Pablos, J., \& Biedma, J. (2013). La evaluación del rendimiento individual. Un instrumento válido para lograr la eficiencia en la gestión de Recursos Humanos en las Administraciones públicas\{The evaluation of individual performance. A valid instrument to achieve efficiency in the manageme. Gestión y Análisis de Políticas Públicas, (10), 1-18.

Ramírez, R., Villalobos, J., \& Herrera, B. (2018). Proceso de talento humano en la gestión estratégica. Opción(18), 2076-2101.

Resolución DC 342 del Instituto Ecuatoriano De Seguridad Social. (2010). Restitución de varios beneficios a favor de trabajadores del IESS amparados por Código del Trabajo y contrato colectivo. Restitución de varios beneficios a favor de trabajadores del IESS amparados por Código del Trabajo y contrato colectivo. Quito, Pichincha, Ecuador: https://n9.cl/no1r.

Robbins, S. (2004). Comportamiento Organizacional[Organizational behavior]. Prentice Hall, 718.

Rodríguez, C., \& Romo, L. (2013). Relación entre Cultura y Valores Organizacionales [Relationship between Culture and Organizational Values]. Conciencia Tecnológica, (45), 12-17.

Rodríguez-Serrano, J. (2004). El modelo de gestión de recursos humanos [The human resources management model]. Barcelona: Editorial UOC.

Torres, W., Espinoza, V., \& Sulca, G. (2017). Panorama sobre la estructura del empleo público en el Ecuador [Overview of the structure of public employment in Ecuador]. Revista Publicando, 4(10), 299-312. 


\section{CIENCIAMATRIA}

Revista Interdisciplinaria de Humanidades, Educación, Ciencia y Tecnología

Año VII. Vol. VII. N¹2. Enero - Junio. 2021

Hecho el depósito de ley: pp201602FA4721

ISSN-L: 2542-3029; ISSN: 2610-802X

Universidad Nacional Experimental Francisco de Miranda (UNEFM). Santa Ana de Coro. Venezuela

Marco Antonio González-Neira; Edwin Joselito Vásquez-Erazo;

Gonzalo Iván Andrade-Mena

Valencia, D., Erazo, J., \& Narváez, C. (2019). El clima organizacional y su incidencia en la motivación del Talento Humano [The organizational climate and its impact on the motivation of human talent]. Revista Arbitrada Interdisciplinaria Koinonía, 1(4), 436-467. http://dx.doi.org/10.35381/r.k.v4i1.464

Vargas, O., \& Quishpe, J. (2019). Análisis ético en la selección del personal en las empresas públicas. Revista Observatorio de la Economía Latinoamericana. https://n9.cl/hk745

Vázquez-Martínez, D., Erazo-Álvarez, J., Narváez-Zurita, C., \& Pozo-Cabrera, E. (2020). La consulta previa, libre e informada en el Ecuador y la necesidad de su codificación. IUSTITIA SOCIALIS, 5(9), 135-159.

Werther, W, \& Davis, K. (1991). Administración de personal y recursos humanos [Personnel and human resources management]. McGRAWHILL/INTERAMERICANA EDITORES, S.A. de C.V. 